\title{
Beyond Play: Conceptualising the Capability of a Good Digital Game to Stimulate Interest in STEM
}

\author{
Shahrul Affendi Ishak and Rosseni Din* \\ STEM Enculturation Research Centre \\ Faculty of Education, Universiti Kebangsaan Malaysia, Selangor, Malaysia \\ https://orcid.org/0000-0001-6019-9400 \\ https://orcid.org/0000-0002-0851-9910 \\ Umi Azmah Hasran \\ Fuel Cell Institute \\ Universiti Kebangsaan Malaysia, Selangor, Malaysia \\ https://orcid.org/0000-0002-1751-2550
}

\begin{abstract}
Digital games are one of the potential pedagogical approaches within STEM teaching and learning. The main idea behind using digital games in STEM contexts is to enhance the children's conceptual understanding and to increase their interest in STEM. The interest in STEM is still an unsolved global issue. Most studies looking into digital games show there to be positive implications when it comes to STEM learning. This gap and the uncorrelated scenario from both the theoretical and practical perspectives need to both be solved. Here we conceptualise the usefulness of STEM digital games for stimulating an interest in STEM, particularly among children from a design perspective. The previous studies are the main qualitative sources for the interpretation of the main argument in this paper. As result, digital games have a strong empirically supportive foundational basis that acts as a medium to stimulate interest. To achieve this, STEM digital games should be designed to be of better quality. Good STEM digital games will contribute to better STEM learning outcomes and meaningful gaming experiences that can contribute to the interest in STEM. This study proposes a comprehensive framework to understand the purpose of the design and development of STEM digital games.
\end{abstract}

Keywords: STEM digital game; STEM game design; STEM interest; 21st century pedagogy

\footnotetext{
*Corresponding author: Rosseni Din, rosseni@ukm.edu.my
} 


\section{Introduction}

Digital games have been known to be one of the best pedagogical approaches to enhancing STEM education, especially for 21st century learners (Dadure et al., 2021; Ishak et al., 2021). STEM is one of the most difficult and unpopular subjects among school students. Since the STEM acronym was introduced in the early 2001 by the U.S National Science Foundation (NSF), the implementation of STEM education in curricular began at that point. The point is to ensure that the students are able to form a relationship with the interdisciplinary STEM subject for the purpose of real world problem solving (Daugherty \& Carter, 2017). Maintaining the interest towards STEM subjects is challenging. Most studies support the empirical results of the STEM learning achievements that use digital games. Based on this result, most studies tend to suggest that digital games are suitable for stimulating the STEM interest.

The lack of STEM interest among school students (primary and secondary) is a global educational issue. To date, the government is still unaware of how to solve this issue (Hashini Kavishtri, 2019; Noorazura, 2020; The Star Online, 2018). This is despite many strategies having been implemented through after school programs, classroom competitions, seminars, science projects, and educational school trips purposely to increase the STEM interest. However, these activities are mainly undertaken to expose the student to and let them experience the real world of STEM. However, this strategy might require a certain cost and only some of the selected students will be able to participate in this program. To make the realworld STEM experience more inclusive and assessable, digital games should be capable of supporting this strategy (Marcelo Leandro et al., 2018; Wu \& Anderson, 2015).

Digital games are one of the modern popular play activities regardless of age or gender. Children mostly spend their leisure time at home playing digital games, either through their parent's computer, through a tablet, or on a smartphone (Dalope \& Woods, 2018). This is for fun and entertainment. The advanced interactive graphic systems of digital games strongly engage them in the virtual world. This scenario in the popular gaming culture should be taken as a precious opportunity. The STEM school curricular results in an early exposure to the subject for children. As suggested, children aged between 10 to 12 years old are in the best stage to be empowered and to have their interest in STEM triggered (Bryan et al., 2016; Koehler et al., 2016). This stage is a transition from the concrete operational to the formal operational stage. Children have a high state of curiosity and experiment in their surroundings as part of a rational interpretation (Jas Laili Suzana, 2016; Kleinman, 2012). STEM learning content is being integrated into digital game mechanics purposely to enhance the STEM learning experience inside or outside the classroom.

There are two types of digital game that are suitable for STEM teaching and learning. Digital games (made for entertainment) are mainly developed for entertainment purposes, while educational digital games (made for education and fun) have integrated learning content to enhance the STEM learning undertaken in a fun and engaging environment. Despite the original purpose of their development, some commercial digital games (e.g.: Minecraft, Foldit, Angry Bird, 
Plant Vs. Zombie, and SimCity) have STEM-related concepts involved that are applicable to enhancing and applying STEM knowledge (Avraamidou et al., 2015; Herodotou, 2018; Keogh, 2014). Studies on digital games prove that using digital games empirically improves the individual STEM learning outcome. However, the idea of digital games being the best way to promote and increase STEM interest can only be found as a statement (Fisher, 2015; Krapp, 1999; Marcelo Leandro et al., 2018; Wan Nor Fadzilah et al., 2017), research implication or future perspective (Ball et al., 2018; Desmond \& Michael, 2016; Halim et al., 2018; Raffety et al., 2016), without any empirical evidence.

In addition, the number of studies explaining how digital games can increase the level of STEM interest is still lacking. There must be supporting evidence to explain why scholars have made significant conclusions on the potential use of digital games to promote STEM interest. Studies show that the correlation of several attributes can be obtained as a scattered result. We strongly believe that these attributes should be combined to create a holistic explanation regarding this issue. We have diverged from the central question to ask and answer how digital games should be designed based on stimulating the player's interest in STEM. By using the data sources from the existing studies, this conceptual paper attempts to understand and provide a comprehensive conceptual framework on how STEM digital games should be designed. To begin with, we define digital games as an indirect teaching tool that can provide a fun and entertaining STEM learning environment via a virtual world to stimulate the individual's interest in STEM.

\section{Good STEM Digital Game}

Defining a good STEM digital game might be subjective as it is a creative product. Every designer and developer will claim that their design is the best even though some people will argue the matter. There are several indicators used to describe a good digital game. Studies have been conducted to understand and identify the factors and attributes that influence what makes a good educational digital game. Since digital games have originated from the computer science field, most common scholars use the MDA framework as a foundation for game design. Game designers use this framework to design a set of game play for the audience and to determine how the audience might interact with the game play. As digital games become educational tools, educational technology has started to study how digital games can be designed and used to facilitate learning. Several models have been proposed to indicate the factor used to design a good educational digital game. However, the models still lack the component needed to explain what a good STEM digital game as a universal product is.

The MDA framework has been practiced in most commercial non-educational digital games made for entertainment purposes. In the educational technology context, scholars in this field focus on both perspectives, specifically education and entertainment. Most models emphasise blending of the pedagogical element, learning content and game elements to achieve the needs of the educational digital game. Some models are too complex and some lack either game or pedagogical elements. This theoretical basis is important for game designers when designing educational digital games. Most game designers come from a computer science background. They might be familiar only with the MDA framework and certain 
models in their field instead of models and frameworks from the educational technology field.

Despite the MDA framework being used in game design studies, the game elements have the same core central elements when designing any digital game. These serve as guidelines. The designer must choose the correct game elements for their game. Each digital game has its own uniqueness. While some elements might work, some might not. A lot is dependent on the purpose of the development. As STEM digital games are purposefully developed to provide a STEM learning environment, it is necessary for both perspectives to be involved, specifically design and education.

The perspectives of computer science and educational technology should be combined to identify the most important attributes for good STEM digital games to help increase the level of STEM interest. Applying the universal design model helps to ensure the quality of the design for a diverse range of users. Among the existing universal design models for digital teaching tool design and development, the latest UDin Model proposed by Rosseni Din suggests that a good digital teaching product should consist of the integration of a theory, pedagogy, strategy, content, and value (Din, 2016, 2019, 2020a, 2020b). Some studies have successfully designed and developed various platform of digital teaching media using the same model. Despite the suitability of this universal design product, the model still lacks a game perspective. Through this paper, we provide an explanation of the elements that should be used in order for a STEM digital game to be designed to stimulate an interest in STEM.

\section{STEM Digital Game Design Input}

Discussing what makes a good STEM digital game can be subjective. Digital games are known as creative products that are developed using technology. Digital games have become part of daily play activities and they are the most popular among children. Since it is a creative product, there is no right or wrong when it comes to designing a digital game so long as it is playable, appeal, and engaging. However, there needs to be a discussion on how to develop a good digital game through the principal design and game elements, which are the two core aspects. Two distinct gaps exist in which the game designer and developer will emphasise designing to achieve entertainment. The educational technologist will use a complex theoretical basis to purposely design the game to achieve the learning outcome (Shi \& Shih, 2015). However, there are no specific guidelines on designing and developing digital games for the STEM context that emphasise these two perspectives.

An interest in STEM can be promoted by playing digital games. The players can be characterised into having more or less preferences in a STEM digital game. This idea reflects the original study by Hidi and Renninger (2006) and Krapp (2007) regarding the educational psychology of interest development. The exposure of the individual (player) to an interesting object (STEM digital game) will create individual interest (interest in STEM). Interest is developed based on four stages. This includes phase 1 - triggered situational interest, phase 2 - maintained 
situational interest, phase 3 - emerging individual interest, and phase 4 - welldeveloped individual interest. The ontogenetic transition from situational to individual interest has been explained by the interaction of a person with the situation (conditional factors). This produces situational interest (actualised state) and later results in individual interest (enduring developmental effect) through internalisation. We have integrated the ontogenetic transition idea by Krapp (1988) into the STEM digital game context (Figure 1).

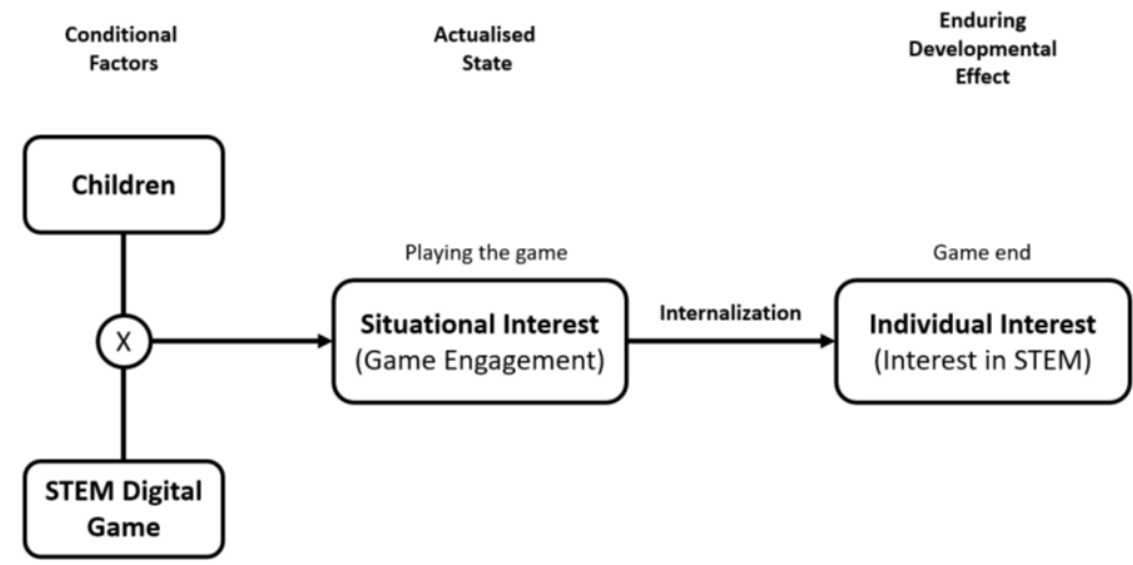

Figure 1: The ontogenetic transition from situational to individual interest via STEM digital games adapted from Krapp (1988)

We view STEM digital games as a combination of learning and entertainment. Any entertainment media or product made for children should have the educational element. Since children have the highest level of curiosity, they tend to explore new things in their surroundings. Digital games should help constructivist learning as well as being fun. To achieve this, the theoretical foundation and practice from the two perspectives involved need to be merged. A collaboration between the game's creative team with educational technologists along with a STEM content expert is the priority. As a universal product, digital game development should have a higher degree of usability. Studies indicate that there are several indicators that can influence good digital game design. Compared to the other universal design attributes, a universal design for digital teaching tools is more precise as it ensures that every aspect of product development will achieve a meaningful learning outcome. However, designing a digital game should consider some of the attributes from the game designer's perspective. We classified the findings into six major indicators, namely theory, learning strategies, pedagogy, the STEM learning content, game elements, and game principal design.

\subsection{The Need for Theory}

Very few studies on digital games have implementing theory as fundamental in game design. In general, theory is useful to explain certain phenomenon which in this context is learning through digital games. However, some of the studies on educational digital games support the usefulness of the theory underpinning and guiding the overall look of the game design (Ahmad et al., 2015; Clark et al., 2015; Elsattar, 2017; Ishak et al., 2021; Kiili, 2005; Mat Zin \& Wong, 2013; Pereira de 
Aguiar et al., 2018; Plass et al., 2015; Rooney, 2012; Sung et al., 2017; Taylor et al., 2017; Wu et al., 2012; Zaibon \& Shiratuddin, 2010). Wu et al. (2012) identified that there are four types of major learning theory used in educational digital games, namely behaviourism, cognitivism, humanism, and constructivism. Elsattar (2017) discovered another four distinct learning theories that are associated with digital games, specifically motivational, sociocultural, emotional, and cognitive (Table 1). The two main purposes of the theory used are 1) to help explain how digital games work in relation to achieving learning (game impact) and 2) to guide the design (game design).

Table 1: Eight major learning theories and their representative principles as suggested by the previous studies.

\begin{tabular}{|c|c|c|}
\hline $\begin{array}{l}\text { Learning } \\
\text { Theories }\end{array}$ & Representative Principles & References \\
\hline Behaviourism & $\begin{array}{l}\text { Direct instruction } \\
\text { Programmed instruction } \\
\text { Social learning theory }\end{array}$ & $\begin{array}{l}\text { (Plass et al., 2015; } \\
\text { Wu et al., 2012; } \\
\text { Zaibon \& } \\
\text { Shiratuddin, 2010) }\end{array}$ \\
\hline Cognitivism & $\begin{array}{l}\text { Attribution theory } \\
\text { Elaboration theory } \\
\text { Cognitive development } \\
\text { Conditions of learning }\end{array}$ & $\begin{array}{l}\text { (Plass et al., 2015; } \\
\text { Wu et al., 2012; } \\
\text { Zaibon \& } \\
\text { Shiratuddin, 2010) }\end{array}$ \\
\hline Humanism & Experiential learning & $\begin{array}{l}\text { (Kiili, 2005; Sung et } \\
\text { al., 2017; Wu et al., } \\
\text { 2012) }\end{array}$ \\
\hline Constructivism & $\begin{array}{l}\text { Social development theory } \\
\text { Case-based learning } \\
\text { Cognitive apprenticeship } \\
\text { Discovery learning } \\
\text { Problem-based learning } \\
\text { Situated learning } \\
\text { Activity theory } \\
\text { Actor-network theory } \\
\end{array}$ & $\begin{array}{l}\text { (Plass et al., 2015; } \\
\text { Wu et al., 2012; } \\
\text { Zaibon \& } \\
\text { Shiratuddin, 2010) }\end{array}$ \\
\hline Motivational & $\begin{array}{l}\text { Intrinsic motivation } \\
\text { Values and interest } \\
\text { Achievement-related goals }\end{array}$ & (Elsattar, 2017) \\
\hline Sociocultural & $\begin{array}{l}\text { Social context of learning } \\
\text { Participatory learning culture } \\
\text { Observational learning } \\
\text { Social interaction design } \\
\text { Relatedness and self-perception } \\
\text { Social aspects of agency } \\
\text { Activity theory }\end{array}$ & (Elsattar, 2017) \\
\hline Emotional & Emotional design & (Elsattar, 2017) \\
\hline Cognitive & $\begin{array}{l}\text { Situated and authentic learning } \\
\text { Transfer of learning } \\
\text { Scaffolding and intermittent } \\
\text { feedback } \\
\text { Interaction design } \\
\text { Information design } \\
\text { Gesture and movement } \\
\text { Dynamic assessment }\end{array}$ & (Elsattar, 2017) \\
\hline
\end{tabular}


Integrating theory into the design helps the designer and developer to produce a specific targeted learning outcome. Even though the design relies on the creativity of the creative team, theory will lead the overall look of the digital gaming experience. The game world is designed based on the specific theory that will determine the engagement and type of gameplay that the user will use to interact with it. However, designing a game that can trigger STEM interest still raises the big question of how it should be designed. We looked through all of the existing theories that have been used in educational game design. As STEM digital games should be central in providing meaningful STEM learning experiences, we put forward experiential learning theory (proposed by David Kolb on 1984) and its principles is the most relevant for this context, which is to stimulate the interest in STEM.

However, using experiential learning theory as the conceptual basis is not strong enough to ensure the stimulation of STEM interest via the digital gaming experience. Since some game designers will integrate more than one theory into the game design (Plass et al., 2015), other theories should be integrated in this context. We have investigated some of the other potential theories that can be integrated. In addition, there is the educational-psychological combination as part of interest development (Hidi \& Renninger, 2006; Krapp, 1999, 2007) and selfdetermination theory (Malone, 1981). By looking at the individual definition of the theory, we believe that blending these three theories will ensure the development of STEM interests. The consequences of these integrated theories will perhaps produce the main output which is STEM interest.

On top of that, the idea of integrating three theories will lead to answering the question on the distinction of STEM educational digital games. Studies have discovered the outputs as a result of using digital games. The outputs are mainly focused on the learning outcome and gaming experience, while fewer studies have been conducted to study how digital games can be associated with interest, especially in the STEM context. The idea of the interrelation of digital games, learning outcomes, meaningful gaming experiences, and STEM interest as the output constructs has been defined by Ishak et al. (2021). We strongly believe that using digital games is not only directly caused by STEM interests. It is also mediated by the learning outcomes and gaming experience. This theory will act to frame the conceptual look of the designed STEM digital game. However, there are still other elements that need to be a part of this universal design, specifically the pedagogy, learning strategies, STEM learning content, game elements and game principal design.

\subsection{The Need for Pedagogy}

Pedagogy is known as the approach to teaching. This is where the teacher commonly uses different approaches to deliver a specific learning content. In the digital game context, pedagogy plays a role in how the digital games may affect the learning of the players. This is also known as teaching using digital games (Becker, 2017). Digital has become one of the best pedagogical approaches in the digital age (Ketamo et al., 2013) despite the popular gaming culture. Digital gamebased learning (DGBL) is the common term used to refer to this pedagogy. Some 
studies indicate that pedagogy is one of the inputs when designing a digital game (Rooney, 2012).

Most of the common terms referring to pedagogy in the digital game context can be found scattered, while some are linked to learning theory. These pedagogies have been grouped into five major domains (Table 2) of instructional approach in the context of digital games. These are known as didactic (Gagné's Nine Events, Reigeluth's Elaboration Theory, and Merrill's First Principles), instructionist (Spiral Instruction, Programmed Instruction, and Direct Instruction), bricolage (Problem-Based Learning, Situated Learning, and Discovery Learning), hermeneutic (Activity Theory, Constructivist Learning Environments, and ARCS), and cognitive (Advance Organisers, Information Processing, and Cognitive Apprenticeship) (Becker, 2017).

Table 2: Types of pedagogy associated with educational digital game design by Becker (2017)

\begin{tabular}{|c|l|}
\hline Instructional Approach & \multicolumn{1}{|c|}{ Description } \\
\hline Didactic & $\begin{array}{l}\text { Prescriptive; outlines what to do and when; does not } \\
\text { provide processes. }\end{array}$ \\
\hline Instructionist & Algorithmic; outlines a set pattern to follow. \\
\hline Bricolage & $\begin{array}{l}\text { Heuristic/ discovery/ experiential; strongly } \\
\text { influenced by what is at hand. }\end{array}$ \\
\hline Hermeneutic & $\begin{array}{l}\text { Descriptive/ explanatory; describing the pedagogical } \\
\text { system or environment. }\end{array}$ \\
\hline Cognitive & $\begin{array}{l}\text { Science-based; designed to facilitate cognitive } \\
\text { processes. }\end{array}$ \\
\hline
\end{tabular}

However, most digital games will be problem based (Chang et al., 2015; Deng et al., 2020; Hussein et al., 2019; Hwang et al., 2017; Rozhkova et al., 2017; Tudor Car et al., 2019). The problem is the core central element of the digital game (Gros, 2015; Mäyrä, 2015; Pulsipher, 2012; Williams, 2017). The central problem is designed through several game mechanics and later it forms a complete game play. In a digital game, the designed game world provides the player with a problem that needs to be solved in the form of a mission. The main goal is set for the player to achieve. The game only comes to an end if the player is able to pass through all of the obstacles. Throughout the game, the players need to construct the own understanding and a way to solve the problem to reach the end of the game. This problem solving reflects what STEM education is all about, helping children to understand scientific phenomena and showing them how to solve realworld problems (Fisher, 2015).

We suggest that problem-based learning is the most important part of the pedagogical element in the universal design of STEM digital games. The problem plays an important role in determining the learning outcome (Masek, 2015). In the STEM digital game context, the problem can be designed based on STEM-related content. The problem should be designed according to the player's cognitive ability. It can be designed in sequence from easy to the hard. This will allow the game designer to explore more possible game challenges. The designed problem related to the topic of STEM will serve to promote the STEM experience for the player. As STEM requires the student to have good problem-solving skills, this 
integrated problem-based approach to the STEM digital game has a high learning potential.

\subsection{The Need for Learning Strategies}

Digital games allow the player to use several learning strategies to understand the game world system (game play). The learning strategy in the educational digital game context refers to how the player uses a certain set of skills to understand the gaming system and to achieve the learning outcome. The player will observe before trying to make generalise on each interaction within the game. The cycle continues every time they move into the new level and challenge until the game end. There are a number of learning strategies that have been discovered in the modern digital age. Terry Heick's model indicates that there are six modern learning strategies in the 21st century, two of which include play and self-directed learning. Play and self-directed learning are the most common learning strategies found to be associated with digital games. Designers need to be aware of these two elements while designing digital games, particularly STEM digital games.

Play is a core resource for learning, especially in childhood. Hoe (2015) described playing digital games as a structured form of play that is either competitive or non-competitive. It is differentiated from normal play activities (spontaneous). Playing digital games involves play-based activities that make people engaged, relaxed and challenged. The player's state of mind is highly conductive towards learning. While playing a digital game, the player is free to experiment, to take risks, to show ambition, to follow their curiosity, and to take the risk of creating, designing, evolving, and connecting in ways that are otherwise impossible under compulsion. Every aspect of logical reasoning matters when it comes to completing the game and achieving the goal (Logan \& Woodland, 2015). The player is in control of the game. This includes an individual's views, ideas, theories, imagination, creativity, interests, and experiences, including their experience of assuming a new identity while learning (e.g.: playing the role of game avatar).

Playing digital games involves a higher level of self-directed learning. Selfdirected learning is rooted in the application of skills (thinking, research, selfmanagement, social skills, and communication skills). Digital games are a medium that is individual-centred. It gives the player further independent practice of comprehension strategies. Even in collaborative multiplayer games, the player needs to identify, determine, and make decisions related to every action taken in the game. They take the initiative without the assistance of others when diagnosing the learning need and when formulating their constructive knowledge purposely to complete the game. To understand how the game system is designed, the players will connect to their background knowledge and schema and monitor their comprehension when evaluating the game mechanics that they are interacting with inside the game. All of this is related to the scientific process which encourages the player's curiosity and discovery. It is also a process of hypothesis formation and testing.

While playing STEM digital games, the students practice their own scientific thinking without even realising that they are doing so. Ishak et al. (2021) 
summarised the core scientific thinking used by players while playing digital games as observing, testing, and drawing conclusions. Students need to solve the problem designed inside the game. To achieve the goal of the STEM digital games, the students need to understand and make assumptions about the game system (observation). This includes predicting and testing their assumptions through several actions (testing), in addition to the results obtained being based on the actions driving the player towards the end of the game (drawing conclusion) (Figure 2). This idea is the same as what STEM education is trying to achieve overall. With STEM educational digital games, students are not only required to solve the designed problem based on their previous existence STEM knowledge but the presence of a magic circle also triggers their basic STEM skills. After winning the game (problem solved), the students are debriefed on the learning content as it relates to declarative knowledge.

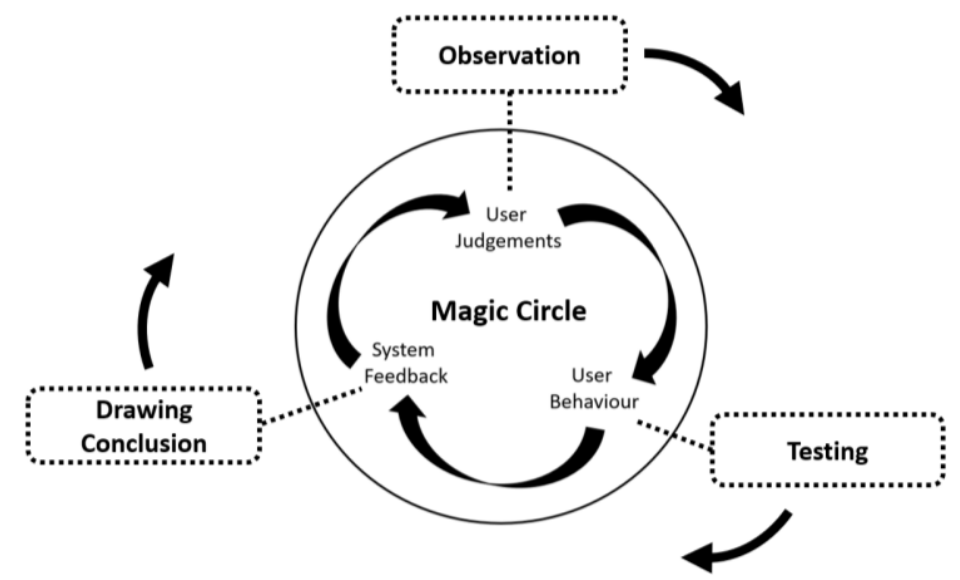

Figure 2: Core basic STEM skills used by the player while playing digital games, adapted from (Avraamidou et al., 2015; Garris et al., 2002; Ishak et al., 2021)

Game designers should pay attention to this perspective. The pedagogy and learning strategy might be similar to certain a degree but they have two distinct views in the context of digital game design. Pedagogy focuses on how to design a problem, while the learning strategy is focused more on how the designed problem should be solved within the digital game. For STEM digital games, the game designer needs to design a problem (issues in the STEM related topic) into the game play while ensuring that the player can use the learning strategy not only to play but also to solve the designed problem. Game designers are free to explore both the design and gameplay otherwise. However, the integrated STEM learning content should suit the player's cognitive ability while still optimising the meaningful gaming experience. As a result, it will inspire in the children the desire to discover on their own as part of the nature of STEM education.

\subsection{The Need for STEM Learning Content}

Learning content is a vital part of educational digital games. Non-educational digital games also use content as part of their design. It is impossible to neglect to include content in digital games. All studies on educational digital game design emphasise the need for learning content for all ranges of user including children (Balli, 2018; Herodotou, 2018; Kiili \& Ketamo, 2017; Lowrie, 2015; van den Heuvel- 
Panhuizen et al., 2013), teenagers (Lester et al., 2014; Marcelo Leandro et al., 2018; Mohd Jamel et al., 2019; Pedersen et al., 2016; Raffety et al., 2016), adults (Brown et al., 2018; Buijs-Spanjers et al., 2020; Gaspar et al., 2020; Kuk et al., 2012; Ross et al., 2014; Vecchia et al., 2015), and the elderly (Cota et al., 2015). In the STEM digital game context, we define STEM learning content as the scientific topic, themes, beliefs, concepts, and facts related to STEM that are often grouped within each subject or learning as part of the knowledge, skills, values and attitudes that are expected to be learned in the digital game.

Science, technology, engineering, and mathematics subjects have the highest number of subtopics, respectively. The integration of STEM education in the past 20 years has been trying to make a connection with each discipline as part of an interdisciplinary subject for students, particularly at the secondary level. By integrating STEM, it allows the students to understand the important of interdisciplinary STEM learning in relation to real world problem solving (Daugherty \& Carter, 2017). The matter of interdisciplinary STEM disciplines has emerged as a new curriculum project, as a range of instructional materials, and as a pedagogical approach. Studies indicate that each STEM discipline has a general definition. This is important for students to understand the subject needs and how they are related to each other.

The idea of integrating STEM topics as the content of a digital game is a good starting point to expand the theoretical foundation underlying a good game design and associated development. The interrelated STEM elements should be highlighted as part of the overall design so then the players are able to figure out and understand the usefulness of applying knowledge from each STEM discipline to drive the entire game. However, the integration of STEM content into the game mechanics (objectives and goals, feedback, challenges, levels, progress bar, rewards and badges, timers or countdowns, competition, and a leader board) will allow the player to interact with the set of rules and feedback loops applied. This interaction with the system is intended to produce enjoyable STEM-based gameplay. To implement all interdisciplinary STEM disciplines in the game, Leung (2019) suggested emphasising science and mathematics in a central role. Engineering acts as a requirement for researching, designing, and producing, while the application of robotics, coding and programming are due to it being technology oriented. To ensure the success of the content, game designers need to collaborate with STEM content experts (STEM teacher) to fulfilling the demands of the STEM curriculum in the design.

\subsection{The Need for Game Elements}

Game elements are a set of component yangs that make up a digital game. The original game theory proposed by John von Neumman and Oscar Morgenstern in 1944 describes games from a mathematical perspective. They stated that a game consists of an agent (player), a strategy, an outcome, and a payoff (reward). The players make a strategy for the purpose of rational action to achieve the outcomes and payoffs. This concept has been developed and used in different perspectives including sociology by Roger Caillois (1961), psychology by Eric Berne (1964), game design by Chris Crawford (2003), and game-based learning by Marc 
Prensky (2007) (Tan, 2016). More game elements have been discovered since that make digital games more appealing and engaging.

The early MDA framework requires game designers to emphasis the mechanics, system, gameplay, and player experience as the core disciplines of game design (Zubek, 2020). The four game elements in the MDA frameworks have mostly been practiced in commercial digital game development instead of educational games. When designers explore their creativity, more elements are being used. Crawford (2003) discovered that a range of game elements are associated with a designer's creative expression including money, interactivity, goals, competitors, and the attacks allowed. Despite the commercial value, educational digital games require the integration of an educational element with the aforementioned game elements. Some of the studies discuss several game elements that act as a factor in successful educational digital games including the core and motivating elements (Adams, 2014; Alaswad \& Nadolny, 2015; Ke, 2016; Mildner et al., 2015; Ralph \& Monu, 2015; Rosly \& Khalid, 2017; Tan, 2016; Vandercruysse \& Elen, 2017).

A recent study on digital games extracted an MDA framework and classified the game elements in detail. The increasing types of game element are due to the designer's creative exploration of the design itself. This is done purposefully to make the game more attractive and competitive. However, some studies (Alaswad \& Nadolny, 2015; Tan, 2016) have categorised the massive number of existing modern game elements into game attributes (essential elements) and game motivating elements (optional elements). Elements such as the player, the character, goals, feedback, rules, and the controls are the main attributes that make a digital game. The optional elements such as badges, leader boards, rewards, challenges, fantasies, narratives, interactions, sensory stimuli, mastery, sociality, sensation, values, threat freedom, and values can be considered by the designer. The motivating elements will help the digital game become more appealing and engaging to the audience. These elements are among the macro design concepts for general educational digital games.

All of these elements (the game's attributes and the game's motivational elements) will be integrated into the game mechanics, resulting in a particular gameplay for the digital game. These game elements can be represented as an artifact. Ralph and Monu (2015) proposed a unified theory for digital games. This theory suggests a different set of game element classes where the interactions of the player (aesthetics; interpreted narrative) with a select artifact (game mechanics, narrative mechanics, technology, and embedded narratives) will produce an experience (dynamics and emergent narrative). From the computer science perspective, this theory is derived from MDA and Tetrad. The three classes of game element have been made due to the game mechanics, narrative mechanics, technology, and embedded narratives as artifacts because they exist independently of any particular player. Aesthetics and interpreted narrative are referred to as the player because they only exist in the player's mind, and finally, dynamics and the emergent narrative are classed as experience because they emerge from the player. 


\subsection{The Needs of Principle Game Design}

Designing educational digital games should consider some core principle designs. As most STEM educational digital games are made purposely for children, designers should consider some of the elements needed to increase the degree of usability. Understanding the player is compulsory and most designers are suggested to use the player-centric approach when it comes to designing digital games (Adams, 2014). The biggest issue when designing games for a diverse range of users is age (Fisher, 2015) and gender (Adams, 2014). Young children might not be able to play hardcore games as they require certain cognitive abilities. Additionally, the game preferences of boys and girls are different. However, designers should understand the targeted player and design a game that both sexes are encouraged to play.

Digital games for children are different from the games are from adults. Their need, skills, and expectations are drastically different. Designing games for children need to be carefully done to ensure their appropriateness. Understanding the player is the key to overcoming this issue by emphasising the player-centric approach. The player-centric approach requires the designer to understand the player (children) and their particular needs. Most designers will use Piaget cognitive development theory as the basis to understand the level of cognitive and motor skills found among children (Adams, 2014; Fisher, 2015). In digital games, the most recognised age categories are preschool and kindergarten (ages 3 to 6), early elementary (ages 5 to 8), upper elementary (ages 7 to 12, the tweens), middle and high school (13 and up, the teens), and the late teens through to mid-20s. Late teens need to be considered because their brains are still developing. These categories of children have their own interests and abilities. This reflects that their brains and physiology are different compared to adults.

Table 3: The appropriateness of digital games based on the age categories adapted from Fisher (2015) and Adams (2014)

\begin{tabular}{|c|l|c|}
\hline Age categories & \multicolumn{1}{|c|}{ Description } & $\begin{array}{c}\text { Level of } \\
\text { design } \\
\text { consideration }\end{array}$ \\
\hline $\begin{array}{c}\text { Babies and } \\
\text { toddlers } \\
0-2 \text { years }\end{array}$ & $\begin{array}{l}\text { They are figuring out the basics. Their } \\
\text { technology use and gameplay are limited. } \\
\text { Their brains and all connected skills are still } \\
\text { developing. The game should be as simple } \\
\text { as it can be. Accelerometers and other tools } \\
\text { for tracking movement (tilting or shaking) } \\
\text { are easier for them. }\end{array}$ & Very high \\
\hline Pre-schoolers & $\begin{array}{l}\text { Pre-schooler are learning everything that } \\
\text { they can about the world. They are } \\
\text { explorers, believe in magic, take pleasure in } \\
\text { mastering tasks, and enjoy showing off their } \\
\text { skills. It is important to foster exploration } \\
\text { and discovery via simple interactions. } \\
\text { Games for them should be simple. }\end{array}$ & High \\
\hline Elementary kids & $\begin{array}{l}\text { They begin to discover their independence } \\
\text { and preferences. They are able to strategise } \\
\text { and keep multiple goals in mind. They are }\end{array}$ & High \\
\hline
\end{tabular}




\begin{tabular}{|c|c|c|}
\hline $6-8$ years & $\begin{array}{l}\text { also able to play more complex games. Kids } \\
\text { at this age frequently play casual games that } \\
\text { are designed for all ages. They also start to } \\
\text { show preferences consistent with gender. }\end{array}$ & \\
\hline $\begin{array}{l}\text { Tweens } \\
9 \text { - } 12 \text { years }\end{array}$ & $\begin{array}{l}\text { Kids at this age are entering their teen years } \\
\text { which means that they can vary wildly in } \\
\text { maturity. They are fully exploring their } \\
\text { identity and social interactions. They are } \\
\text { unlikely to choose to play educational games } \\
\text { on their own unless they are presented in a } \\
\text { school setting. Games that can foster STEM } \\
\text { thinking are very important for them. They } \\
\text { play a large number of casual games. The } \\
\text { type of games chosen by boys and girls are } \\
\text { different for this age range. }\end{array}$ & Moderate \\
\hline $\begin{array}{c}\text { Teens } \\
13 \text { and above }\end{array}$ & $\begin{array}{l}\text { Teens are basically adults who have a lack of } \\
\text { life experience. At this age, they are able to } \\
\text { reason, plan and explore their identities. } \\
\text { Designers can help to introduce information } \\
\text { and interventions for at-risk behaviour. } \\
\text { They will play games that adults play. }\end{array}$ & Moderate \\
\hline
\end{tabular}

Gender preferences should be considered when designing a digital game. Boys and girls have different interests and preferences. This is reflected in their game choice. Children enter their teenage years between the ages of 9 - 12 years old and they very wildly in maturity (Fisher, 2015; Jas Laili Suzana, 2016; Santrock, 2016). Boys prefer racing games and first-person shooters whereas girls tend to choose more social and caregiving games. However, Fisher (2015) stated that children at this age have been identified as playing more casual games designed for all ages and both genders. Most popular casual digital games that ignore gender while also being associated with STEM-related concepts include Angry Bird, Plant Vs Zombie, SimCity, and Minecraft (Avraamidou et al., 2015; Herodotou, 2018; Keogh, 2014).

Children in the digital age are more IT literate. Their exposure to digital devices at an early age allows them to learn any gameplay very fast. As digital games in the third age are more focused on the children's engagement with the games, digital games should be fast and easy to start. This means that they require only a little or no technical support and that they provide something useful for the teacher. They should not restrict the teacher's classroom management (Ketamo et al., 2013). As for the game designers, they need to fulfil as many of those requirements as possible. Some design considerations need to be taken into account. Some of the previous studies (Adams, 2014; Chiasson \& Gutwin, 2005) suggest that most digital games for children should consider the elements that involve fantasy and the imagination. This is in addition to hand-eye coordination, logic development, systematic thinking, immediate versus long-term goals, simple and focused visual design, less linguistic complexity, allowing for experimentation, less reading, and appropriate content. Boys commonly have more interest in playing digital games compared to girls. To solve this, Kaye Elling's Five Cs Model (2006) suggests that designers should emphasise more 
elements to do with characterisation, context, control, customisation, and creativity in the game design to engage game players who are girls.

\section{STEM Digital Game Output 4.1 STEM Learning Outcome}

All studies on STEM educational digital games indicate that learning achievements are the main output, regardless of the user demographics. The STEM learning achievements and the improvements obtained using digital games have been studied from the educational perspective. Learning theory is able to explain how the learners construct and interpret the learning content via gameplay. We strongly believe that digital games are an individual-centred medium that requires self-directed learning. By using STEM digital games, the studies indicate that the learning that occurs is constructive.

Players construct their own knowledge by interacting with the elements designed inside the game. The integration of the game elements and STEM related content forms the gameplay. Some studies argue that the game should minimise the game elements as they will distract the player from the learning content. However, most of the present studies support using a balance of these two main elements (Herodotou, 2018; Kiili \& Ketamo, 2017; Marcelo Leandro et al., 2018; Mohd Jamel et al., 2019; Pedersen et al., 2016). This means that the player can achieve their learning goals within a playful environment. It is important to consider that digital games are not a tool to replace the teacher. They are a teaching tool to enhance STEM teaching and learning.

Knowledge gained as part of a learning achievement is known as either declarative (knowing what) or procedural (knowing how). Most common educational digital game studies only state that the learning achievement or learning outcome is one where the player gains knowledge. Some have stated that the results from the pre- and post-tests indicate that there is an improvement in the level of STEM conceptual understanding. This result has mostly been tested among teen and adult populations (Brown et al., 2018; Buijs-Spanjers et al., 2020; Gaspar et al., 2020; Vecchia et al., 2015). For people that have a well-developed level of brain function, their learning and conceptual understanding will improve a lot. They will be able to make a connection between what they get from play and what might be applicable in real life.

When it comes to the children's perspective, their developing brain's function and limited cognitive ability means that both declarative and procedural knowledge do not work at the same time. We suggest that the actual knowledge gained by playing digital games is more based on declarative knowledge than the procedural equivalent. While playing, visual interactions and gameplay via the STEM digital game allow the children to grab the scientific facts, rules, and concepts focused on a particular STEM related topic (Ishak et al., 2021). Their procedural knowledge might be subliminal as children are able to understand the learning content as what it is, including the visual representation of how the scientific facts, rules, and concepts inside the game world allow them to understand it for the purpose of a real-world application. However, they might 
not be able to experience and use the knowledge at present, even it is still valuable for them.

\subsection{Meaningful Gaming Experience}

The gaming experience is a major part of playing digital games. Some studies have explained why players become engaged in a digital game. Well-designed gameplay should give the players full implicit control and allow them to respond intuitively to every action taken. Most studies agree that digital games act as pleasurable learning engine that deliver deeply intrinsic motivating experiences. The flow of the experience while playing is the key to the engagement. The player's skill versus difficulty should be maintained and balanced within the game flow. Boredom will happen when the player's skill is high while the game difficulty is low. Anxiety occurs when the player's skills is low while the game difficulty is high. To ensure that the players are engaged and experiencing the game world fully, designers should pay attention to these two factors while designing the gameplay. On top of that, the game is fun and engaging because it transports the player into new realities and satisfies their need for achievement and recognition while embodying a situated practice or epistemic experience.

Throughout this experience while playing the digital game, high engagement towards the game causes the game experience to be meaningful. There are a few studies that indicate this meaningful experience through digital games (Oliver et al., 2015; Rogers et al., 2017; Swayne, 2015). Players feel that the game is meaningful because of the connection within the designed game world. Rogers (2017) stated that a meaningful game helps the player to experience a strong and deep connection to the characters in the game. This is in addition to the story of the game and the moral choices allowed by the game. Their study indicates that meaningfulness is a result of the connection between the player and the in-game character compared to the story and moral choices. Other scholars (Lew et al., 2019; Oliver et al., 2015) indicate that the player engages in a meaningful experience that shows as self-determinant due to their need for autonomy (free choice), while their competence (mastery) and relatedness (social connection) are fulfilled.

We strongly believe that the STEM digital game should emphasise autonomy, competence, and relatedness. Autonomy empowers the player to meaningfully shape the narrative of the game. It allows them to act with volition in their exploration of the virtual world. They are in control of their character in the digital world. Competence allows the player to feel mastery as the game progresses while relatedness allows the player to feel a connection with the character and the story inside the game. As for the STEM context, the meaningfulness of the experience can be seen if the digital world and the gameplay are both well-designed in relation to the STEM related concept. Exposing children to this virtual world lets them feel self-determined in relation to the game. This STEM gaming experience perhaps gets them hooked as they are empowered to control the designed digital world, to master the level, and to feel a strong connection with the character and story embodied in the game. 


\subsection{STEM Interest}

The interest in STEM is the most common statement stated by scholars when referring to the potential use of digital game in the STEM context. Edward Thorndike (1935), a founder of modern educational psychology, has indicated that interest is a psychological construct that can be changed. The changes might be influenced by the internal or external factors of the individual. The idea of using digital games to stimulate interest has been found in the work of Squire (2011). He mentioned that by playing Civilization, his engagement in the game world triggered him to become a historian (Squire, 2011). This statement seems to have been reflected in most of the studies on STEM digital games. As all of the empirical results show that the learners have to improve their STEM learning, most scholars tend to suggest that games have big implications when it comes to the interest in STEM.

Studies indicate that the STEM interest can be used to look into the perception of individuals. Most of the students will have a negative perception of the STEM subject, and only a few might like it. There are several attributes that can represent the STEM interest. In general, individuals that have an interest in STEM will pay more attention. Studies (Mohd Shahali et al., 2018; Mohd Shahali et al., 2016; Mohtar et al., 2019) suggest that the interest in STEM can be identified by looking at the interest in STEM subjects, the interest in STEM careers, and their involvement in STEM-related activities.

\section{The Way Forward and Future Perspectives}

The existing models drawn from educational technology and digital game design should be combined. We believe that the input integrates the core elements required to achieve the output of a developed STEM digital game. As we have conceptualised the capability of the digital game to stimulate the interest in STEM, further research needs to be conducted to measure the related constructs on input and output (Figure 3). A good STEM digital game design consists of theory, pedagogy, the learning strategy, the STEM learning content, game elements, and design principle that together will produce a better STEM learning outcome and gaming experience that perhaps results in an interest in STEM among children.

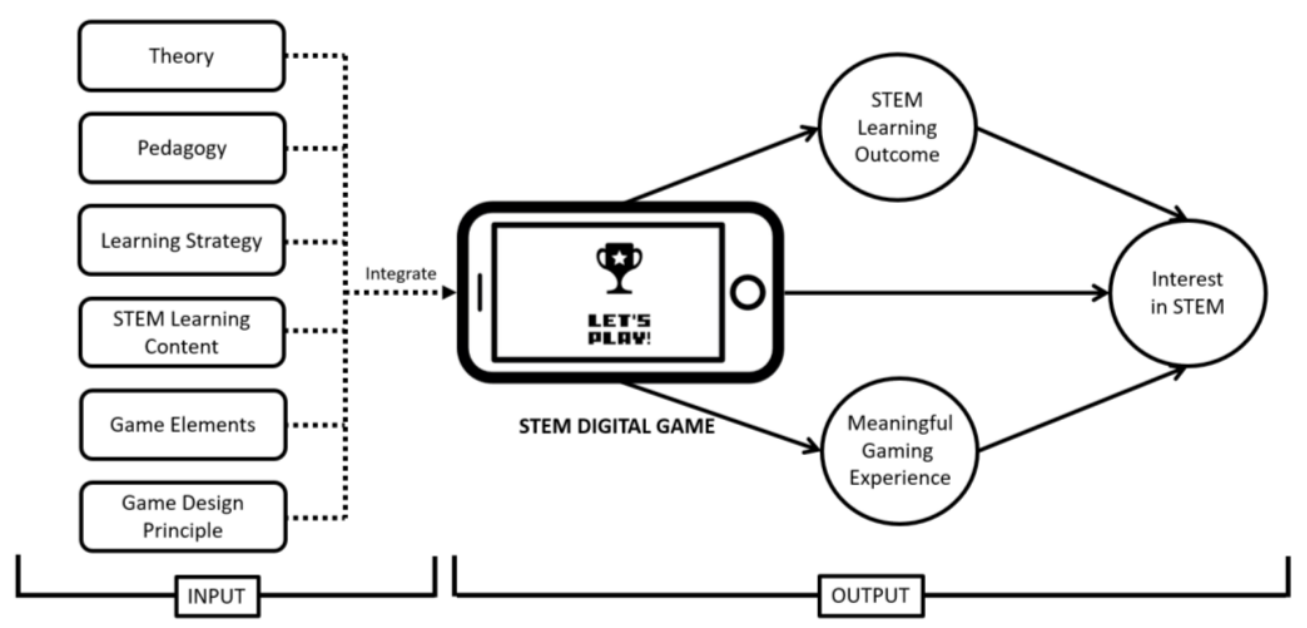

Figure 3: Proposed framework for the STEM Digital Game 
As a form of digital teaching media, a consideration of both computer science and an educational perspective as part of this conceptualisation framework might be useful for both industry (game designer, game developer, game programmer, and game artist) and research purposes. This framework provides a comprehensive foundation for what the STEM digital game should be in terms of its design once it has been developed. Another future perspective that should be taken into account by this study is inclusive of the instruments used to measure the STEM digital game design contracts and output constructs of the designed game. The interrelationship of the construct-purposed output constructs needs to identify whether the game designer has reached the standard required for a good quality STEM digital game.

\section{Conclusion}

In conclusion, STEM digital games are a unique medium that can provide huge benefits for children in the digital age. Digital games are no longer been viewed as solely entertainment media. They have a rich potential for teaching and learning purposes. Children are not only getting the STEM gaming experience there is also the learning obtained by playing the digital game. This can contribute to increasing their interest in STEM. As interest is something that can be triggered and developed, digital games play a major potential role in solving the issue regarding the lack of STEM interest. However, to achieve that goal, STEM digital games should be good quality in terms of the design. The lack of studies emphasising STEM digital games led this study to conceptualise the actual need and potential of STEM digital games. This study proposes and suggests that STEM digital games should be designed based on integration theory, pedagogy, learning strategy, STEM learning content, game elements and design principles as part of a universal design. By ensuring the presence of universal input elements, the STEM digital game will produce a better STEM learning outcome and meaningful gaming experience. We propose that a good STEM digital game will not only have a direct effect on the level of STEM interest but that this might also be mediated by the STEM learning outcome and meaningful gaming experience.

\section{Acknowledgement}

We would like to convey our utmost appreciation to the STEM Enculturation Research Centre (Faculty of Education, Universiti Kebangsaan Malaysia) for the STEM \& Minda (GG-2021-002) and Futuristik (GG-2021-014) grant to support publication workshops. We are thankful to FPEND and UKM for Dana Pecutan Penerbitan 2021 to support the publication and proofreading of this study. Many thanks go to all of the researchers under the Personalised Education Research Group and Geran Universiti Penyelidikan (GUP-2016-039) for their financial, intellectual, spiritual, and moral support.

\section{References}

Adams, E. (2014). Fundamentals of Game Design (Third ed.). Pearson Education.

Ahmad, M., Rahim, L. A., \& Arshad, N. I. (2015, August 24-27). Towards an Effective Modelling and Development of Educational Games with Subject-Matter: A MultiDomain Framework. 2015 5th International Conference on IT Convergence and Security (ICITCS). 
Alaswad, Z., \& Nadolny, L. (2015). Designing for Game-Based Learning: The Effective Integration of Technology to Support Learning. Journal of Educational Technology Systems, 43(4), 389-402. https:// doi.org/10.1177/0047239515588164

Avraamidou, A., Monaghan, J., \& Walker, A. (2015). Mathematics and Non-School Gameplay. In T. Lowrie \& R. J. (Zevenbergen) (Eds.), Digital Games and Mathematics Learning: Potential, Promises and Pitfalls (pp. 11-34). Springer. https://doi.org/10.1007/978-94-017-9517-3_2

Ball, C., Huang, K.-T., Cotten, S. R., \& Rikard, R. V. (2018). Gaming the SySTEM: The Relationship Between Video Games and the Digital and STEM Divides. Games and Culture, XX(X), 1-28. https://doi.org/10.1177/1555412018812513

Balli, F. (2018). Developing Digital Games to Address Airway Clearance Therapy in Children With Cystic Fibrosis: Participatory Design Process. JMIR Serious Games, 6(4), e18. https://doi.org/10.2196/games.8964

Becker, K. (2017). Choosing and Using Digital Games in the Classroom: A Practical Guide (1 ed.). Springer International Publishing. https://doi.org/10.1007/978-3-31912223-6

Brown, C. L., Comunale, M. A., Wigdahl, B., \& Urdaneta-Hartmann, S. (2018). Current climate for digital game-based learning of science in further and higher education. FEMS Microbiology Letters, 365(21). https://doi.org/10.1093/femsle/fny237

Bryan, L. A., Moore, T. J., Johnson, C. C., \& Roehrig, G. H. (2016). Integrated STEM Education. In C. C. Johnson, E. E. Peters-Burton, \& T. J. Moore (Eds.), STEM Road Map: A Framework for Integrated STEM Education (pp. 23-37). Routledge.

Buijs-Spanjers, K. R., Hegge, H. H. M., Cnossen, F., Jaarsma, D. A. D. C., \& de Rooij, S. E. (2020). Reasons to Engage in and Learning Experiences From Different Play Strategies in a Web-Based Serious Game on Delirium for Medical Students: Mixed $\begin{array}{lllll}\text { Methods Design. JMIR Serious Games, 8(3), e18479. } & \text {. }\end{array}$ https://doi.org/10.2196/18479

Chang, C.-S., Chen, J.-F., \& Chen, F.-L. (2015). Development And Design Of Problem Based Learning Game-Based Coursware. International Conference e-Learning 2015. https:// files.eric.ed.gov/fulltext/ED562503.pdf

Chiasson, S., \& Gutwin, C. (2005). Design Principles for Children's Technology. Human Computer Interaction, 7(2). https://hotsoft.carleton.ca/ sonia/content/Chiasson_HCI_TR_2005_02_Design .pdf

Clark, D. B., Sengupta, P., Brady, C. E., Martinez-Garza, M. M., \& Killingsworth, S. S. (2015). Disciplinary integration of digital games for science learning [journal article]. International Journal of STEM Education, 2(1), 2. https:// doi.org/10.1186/s40594-014-0014-4

Cota, T. T., Ishitani, L., \& Jr., N. V. (2015). Mobile Game Design For The Elderly: A Study With Focus on The Motivation To Play. Computers in Human Behavior, 51, 96-105. https://doi.org/10.1016/j.chb.2015.04.026

Dadure, P., Pakray, D. P., \& Bandyopadhyay, S. (2021). Game-Based Learning: A Future Research Agenda. In Z. Gulzar \& A. A. Leema (Eds.), Machine Learning Approaches for Improvising Modern Learning Systems (pp. 50-71). IGI Global. https:// doi.org/10.4018/978-1-7998-5009-0.ch003

Dalope, K. A., \& Woods, L. J. (2018). Digital Media Use in Families: Theories and Strategies for Intervention. Child Adolesc Psychiatr Clin $N$ Am, 27(2), 145-158. https://doi.org/10.1016/j.chc.2017.11.001

Daugherty, M. K., \& Carter, V. (2017). The Nature of Interdisciplinary STEM Education. In M. J. de Vries (Ed.), Handbook of Technology Education (pp. 1-13). Springer International Publishing. https://doi.org/10.1007/978-3-319-38889-2_12-1 
Deng, L., Wu, S., Chen, Y., \& Peng, Z. (2020). Digital game-based learning in a Shanghai primary-school mathematics class: A case study. Journal of Computer Assisted Learning, 36(5), 709-717. https://doi.org/https://doi.org/10.1111/jcal.12438

Desmond, B., \& Michael, D. (2016). Developing Game-Based Learning Requirements to Increase Female Middle School Students Interest in Computer Science. Proceedings of the Human Factors and Ergonomics Society Annual Meeting, 60(1), 380-384. https://doi.org/10.1177/1541931213601086

Din, R. (2016). Notes from the Chief Editor: On Designing Personalized Learning. Journal of Personalized Learning, 2(1), 1-3. http://spaj.ukm.my/jplearning/index.php/jplearning/article/view/108

Din, R. (2019). Partial Least Square Structural Equation Modeling In The Final Phase of Product and Instrument Development Using Universal Design and Agile Development Model. 11th International Conference of Numerical Analysis in Engineering (NAE). 4041. 20-22 August, Hotel Bangi Putrajaya, Selangor.

Din, R. (2020a). Partial Least Square Structural Equation Modelling in the Final Phase of Product and Instrument Development using Universal Design and Agile Development Model. Jurnal Kejuruteraan SI, 3(1), 103-109. https:// doi.org/10.17576/jkukm-2020-si3(1)-16

Din, R. (2020b). Notes from The Chief Editor: On Universal Design and Agile Development. Journal of Personalized Learning, 3(1), 1-7.

Elsattar, H. K. H. A. (2017, 23-25 May 2017). Designing for Game-based Learning Model: The Effective Integration of Flow Experience and Game Elements to Support Learning. 2017 14th International Conference on Computer Graphics, Imaging and Visualization,

Fisher, C. (2015). Designing Games for Children: Developmental, Usability, and Design Considerations for Making Games for Kids. Focal Press.

Garris, R., Ahlers, R., \& Driskell, J. E. (2002). Games, Motivation, and Learning: A Research and Practice Model. Simulation \& Gaming, 33(4), 441-467. https:// doi.org/10.1177/1046878102238607

Gaspar, J. D. S., Lage, E. M., Silva, F. J. D., Mineiro, É., Oliveira, I. J. R. D., Oliveira, I., . Reis, Z. S. N. (2020). A Mobile Serious Game About the Pandemic (COVID-19 Did You Know?): Design and Evaluation Study. JMIR Serious Games, 8(4), e25226. https://doi.org/10.2196/25226

Gros, B. (2015). Integrating of Digital Games in Learning and E-Learning Environments: Connecting Experiences and Context. In T. Lowrie \& R. J. (Zavenbergen) (Eds.), Digital Games and Mathematics Learning: Potential, Promises and Pitfalls (pp. 35-53). Springer.

Halim, L., Rahman, N. A., Wahab, N., \& Mohtar, L. E. (2018). Factors influencing interest in STEM careers: An exploratory factor analysis. Asia-Pacific Forum on Science Learning and Teaching, 19(2). https://www.eduhk.hk/apfslt/v19_issue2/rahman/page9.htm\#a

Hashini Kavishtri, K. (2019). Lack of interest in STEM subjects worrying. https://www.nst.com.my/news/nation/2019/11/535682/lack-interest-stemsubjects-worrying

Herodotou, C. (2018). Mobile games and science learning: A comparative study of 4 and 5 years old playing the game Angry Birds. British Journal of Educational Technology, 49(1), 6-16. https://doi.org/10.1111/bjet.12546

Hidi, S., \& Renninger, K. A. (2006). The Four-Phase Model of Interest Development. Educational Psychologist, 41(2), 111-127. https://doi.org/10.1207/s15326985ep4102_4

Hussein, M. H., Ow, S. H., Cheong, L. S., Thong, M., \& Ebrahim, N. A. (2019). Effects of Digital Game-Based Learning on Elementary Science Learning: A Systematic 
Review. IEEE Access, https:// doi.org/10.1109/ACCESS.2019.2916324

Hwang, G.-J., Hsu, T.-C., Lai, C.-L., \& Hsueh, C.-J. (2017). Interaction of problem-based gaming and learning anxiety in language students' English listening performance and progressive behavioral patterns. Computers $\mathcal{E}$ Education, 106, 26-42. https://doi.org/https://doi.org/10.1016/j.compedu.2016.11.010

Ishak, S. A., Din, R., \& Hasran, U. A. (2021). Defining Digital Game-Based Learning for Science, Technology, Engineering, and Mathematics: A New Perspective on Design and Developmental Research. Journal of medical Internet research, 23(2), e20537.

Jas Laili Suzana, J. (2016). Psikologi Perkembangan: Psikologi Kanak-Kanak dan Remaja [Developmental Psychology: Child and Adolescent Psychology]. Dewan Bahasa dan Pustaka.

Ke, F. (2016). Designing and integrating purposeful learning in game play: a systematic review. Educational Technology Research and Development, 64(2), 219-244. https://doi.org/10.1007/s11423-015-9418-1

Keogh, B. (2014). Paying Attention to Angry Birds: Rearticulating Hybrid Worlds and Embodied Play Through Casual iPhone Games. In G. Goggin \& L. Hjorth (Eds.), The Routledge Companion to Mobile Media (pp. 276-275). Routledge.

Ketamo, H., Kiili, K., Arnab, S., \& Dunwell, I. (2013). Integrating games into the classroom: towards new teachership. In S. de Freitas, M. Ott, M. M. Popescu, \& I. Stanescu (Eds.), New Pedagogical Approaches in Game Enhanced Learning: Curriculum Integration (pp. 534-537). IGI Global. https://doi.org/http://dx.doi.org/10.4018/978-1-4666-3950-8.ch007

Kiili, K. (2005). Digital game-based learning: Towards an experiential gaming model. The Internet and Higher Education, 8(1), 13-24. https://doi.org/https://doi.org/10.1016/j.iheduc.2004.12.001

Kiili, K., \& Ketamo, H. (2017). Evaluating Cognitive and Affective Outcomes of a Digital Game-Based Math Test. IEEE Transactions on Learning Technologies, PP(99), 1-10. https://doi.org/10.1109/TLT.2017.2687458

Kleinman, P. (2012). The Science of The Mind. Advantage Quest Publication.

Koehler, C., Binns, I. C., \& Bloom, M. A. (2016). The Emergence of STEM. In C. C. Johnson, E. E. Peters-Burton, \& T. J. Moore (Eds.), STEM Road Map: A Framework for Integrated STEM Education (pp. 13-22). Routledge.

Krapp, A. (1999). Interest, motivation and learning: An educational-psychological perspective. European Journal of Psychology of Education, 14(1), 23-40. https://doi.org/10.1007/BF03173109

Krapp, A. (2007). An educational-psychological conceptualisation of interest. International Journal for Educational and Vocational Guidance, 7(1), 5-21. https:// doi.org/10.1007/s10775-007-9113-9

Kuk, K., Jovanovic, D., Jokanovic, D., Spalevic, P., Caric, M., \& Panic, S. (2012). Using a game-based learning model as a new teaching strategy for computer engineering. Turkish Journal of Electrical Engineering and Computer Sciences, 20(2), 1312-1331. https://doi.org/10.3906/elk-1101-962

Lester, J. C., Spires, H. A., Nietfeld, J. L., Minogue, J., Mott, B. W., \& Lobene, E. V. (2014). Designing game-based learning environments for elementary science education: A narrative-centered learning perspective. Information Sciences, 264, 4-18. https:// doi.org/10.1016/j.ins.2013.09.005

Lew, V. K., Smith, J., Reuss, N., Zhang, X., Gulliuzo, J., \& Frederick, C. M. (2019). Relatedness in gaming: the effect in-game touch has on player connection. SN Applied Sciences, 2(1), 59. https://doi.org/10.1007/s42452-019-1859-4 
Logan, T., \& Woodland, K. (2015). Digital Games and Mathematics Learning: The State of Play. In T. Lowrie \& R. J. (Zavenbergen) (Eds.), Digital Games and Mathematics Learning: Potential, Promises and Pitfalls (pp. 277-304). Springer. https://doi.org/10.1007/978-94-017-9517-3_14

Lowrie, T. (2015). Digital Games, Mathematics and Visualspartial Reasoning. In T. Lowrie \& R. J. (Zevenbergen) (Eds.), Digital Games and Mathematics Learning: Potential, Promises and Pitfalls (pp. 71-92). Springer. https://doi.org/10.1007/978-94-0179517-3_5

Malone, T. W. (1981). Toward a Theory of Intrinsically Motivating Instruction*. Cognitive Science, 5(4), 333-369. https://doi.org/10.1207/s15516709cog0504_2

Marcelo Leandro, E., Gabriela Trindade, P., Ivana Lima, L., \& Thiago Troina, M. (2018). Mobile Game-Based Learning in STEM Subjects. In D. B. A. Mehdi Khosrow-Pour (Ed.), Encyclopedia of Information Science and Technology, Fourth Edition (pp. 63766387). IGI Global. https:/ / doi.org/10.4018/978-1-5225-2255-3.ch554

Masek, A. (2015). Pendekatan Inovatif Melalui Pembelajaran Berasaskan Masalah [Innovative Approach Through Problem-Based Learning]. In A. Masek (Ed.), Pembelajaran Berasaskan Masalah (pp. 1-38). Dewan Bahasa dan Pustaka.

Mat Zin, N. A., \& Wong, S. Y. (2013). Design and Evaluation of History Digital Game Based Learning (DGBL) Software. Journal of Next Generation Information Technology, 4, 9-24. https://doi.org/10.4156/jnit.vol4.issue4.2

Mäyrä, F. (2015). Mobile Games. In R. Mansell \& P. H. Ang (Eds.), The International Encyclopedia of Digital Communication and Society (First Edition ed., pp. 1-6). WileyBlackwell. https://doi.org/10.1002/9781118290743.wbiedcs014

Mildner, P., Stamer, N., \& Effelsberg, W. (2015). From Game Characteristics to Effective Learning Games. In S. Göbel, M. Ma, J. Baalsrud Hauge, M. F. Oliveira, J. Wiemeyer, \& V. Wendel (Eds.), Serious Games: First Joint International Conference, JCSG 2015, Huddersfield, UK, June 3-4, 2015, Proceedings (pp. 51-62). Springer International Publishing. https://doi.org/10.1007/978-3-319-19126-3_5

Mohd Jamel, F., Ahmad, J. N., \& Ali, M. (2019). The Needs Analysis in Game-Based STEM Module Development for KSSM Science Teachers. International Journal of Recent Technology and Engineering, 8(3), 6622-6628. https://doi.org/10.35940/ijrte.C5655.098319

Mohd Shahali, E. H., Halim, L., Rasul, M., Osman, K., \& Mohamad Arsad, N. (2018). Students' interest towards STEM: a longitudinal study. Research in Science $\mathcal{E}$ Technological Education, 37, 1-19. https://doi.org/10.1080/02635143.2018.1489789

Mohd Shahali, E. H., Halim, L., Rasul, M. S., Osman, K., \& Zulkifeli, M. A. (2016). STEM Learning through Engineering Design: Impact on Middle Secondary Students' Interest towards STEM. EURASIA Journal of Mathematics Science and Technology Education, 1189-1121. https:/ / doi.org/10.12973/eurasia.2017.00667a

Mohtar, L., Halim, L., Abd Rahman, N., Maat, S., Iksan, Z., \& Osman, K. (2019). A Model of Interest in STEM Careers Among Secondary School Students. Journal of Baltic Science Education, 18, 404-416. https:/ / doi.org/10.33225/jbse/19.18.404

Noorazura, A. R. (2020). Kurang membaca punca kemerosotan STEM [Lack of Reading is the root cause of STEM decline]. BH Online. https://www.bharian.com.my/berita/pendidikan/2019/04/558101/kurangmembaca-punca-kemerosotan-stem

Oliver, M. B., Bowman, N. D., Woolley, J. K., Rogers, R., Brett I. Sherrick, \& Chung, M.-Y. (2015). Video Games as Meaningful Entertainment Experiences. Psychology of Popular Media Culture, 1-16. https://doi.org/10.1037/ppm0000066

Pedersen, M. K., Svenningsen, A., Dohn, N. B., Lieberoth, A., \& Sherson, J. (2016). DiffGame: Game-based Mathematics Learning for Physics. Procedia - Social and 
Behavioral Sciences, 228(Supplement $\quad$ C), 316-322. https:// doi.org/10.1016/j.sbspro.2016.07.047

Pereira de Aguiar, M., Winn, B., Cezarotto, M., Battaiola, A. L., \& Gomes, P. V. (2018). Educational Digital Games: A Theoretical Framework About Design Models, Learning Theories and User Experience. In A. Marcus \& W. Wang (Eds.), Design, User Experience, and Usability (DUXU) 2018, LNCS 10918 (pp. 165-184). Springer International Publishing. https://doi.org/10.1007/978-3-319-91797-9_13

Plass, J. L., Homer, B. D., \& Kinzer, C. K. (2015). Foundations of Game-Based Learning. Educational Psychologist, 50(4), 258-283. https://doi.org/10.1080/00461520.2015.1122533

Pulsipher, L. (2012). Game Design-How to Create Video and Tabletop Games, Start to Finished. McFarland \& Company Publisher.

Raffety, C., Prawat, T., Richter, J., Hamilton, R. F., Schelvan, M., Jones, P., \& Holian, A. (2016). Developing Serious Games to Improve Learning and Increase Interest in STEM Careers for Middle School Students: The Mice of Riddle Place ${ }^{\circledR}$. In C. Allison, L. Morgado, J. Pirker, D. Beck, J. Richter, \& C. Gütl (Eds.), Immersive Learning Research Network: Second International Conference, iLRN 2016 Santa Barbara, CA, USA, June 27 - July 1, 2016 Proceedings (pp. 132-143). Springer International Publishing. https://doi.org/10.1007/978-3-319-41769-1_11

Ralph, P., \& Monu, K. (2015). Toward a Unified Theory of Digital Games. The Computer Games Journal, 4(1), 81-100. https://doi.org/10.1007/s40869-015-0007-7

Rogers, R., Woolley, J., Sherrick, B., Bowman, N. D., \& Oliver, M. B. (2017). Fun Versus Meaningful Video Game Experiences: A Qualitative Analysis of User Responses [journal article]. The Computer Games Journal, 6(1), 63-79. https:// doi.org/10.1007/s40869-016-0029-9

Rooney, P. (2012). A Theoretical Framework for Serious Game Design: Exploring Pedagogy, Play and Fidelity and their Implications for the Design Process. International Journal of Game-Based Learning, 2(4), 41-60. https://doi.org/10.4018/ijgbl.2012100103

Rosly, R. M., \& Khalid, F. (2017). Gamifikasi : Konsep dan Implikasi dalam Pendidikan. In R. M. Rosly, N. A. Razali, \& N. A. Jamilluddin (Eds.), Pembelajaran Abad ke-21: Trend Integrasi Teknologi (pp. 144-154). Penerbit UKM.

Ross, A. M., Fitzgerald, M. E., \& Rhodes, D. H. (2014). Game-based Learning for Systems Engineering Concepts. Procedia Computer Science, 28(Supplement C), 430-440. https://doi.org/10.1016/j.procs.2014.03.053

Rozhkova, S., Rozhkova, V., Lasukov, V., \& Chervach, M. (2017, 6-8 March, 2017). Educational Games As A Form of Problem-Based Learning. 11th International Technology, Education and Development Conference, Valencia, Spain.

Santrock, J. W. (2016). Children (13th ed.). McGrow-Hill Education.

Shi, Y.-R., \& Shih, J.-L. (2015). Game Factors and Game-Based Learning Design Model. International Journal of Computer Games Technology, 1-11. https://doi.org/10.1155/2015/549684

Squire, K. (2011). Video Game and Learning: Teaching and Participatory Culture in The Digital Age. Teachers College Press.

Sung, H.-Y., Hwang, G.-J., Lin, C.-J., \& Hong, T.-W. (2017). Experiencing the Analects of Confucius: An experiential game-based learning approach to promoting students' motivation and conception of learning. Computers \& Education, 110, 143-153. https://doi.org/10.1016/j.compedu.2017.03.014

Swayne, M. (2015, 28 July 2017). Video games can power up from merely fun to meaningful experiences. Penn State News. Retrieved 23 March 2019 from 
https://news.psu.edu/story/353213/2015/04/15/research/video-games-canpower-merely-fun-meaningful-experiences

Tan, W. H. (2016). Gamifikasi dalam Pendidikan: Pembelajaran Berasaskan Permainan [Gamification in Education: Game-Based Learning]. Penerbit Universiti Pendidikan Sultan Idris.

Taylor, M., Baskett, M., Reilly, D., \& Ravindran, S. (2017). Game Theory for Computer Games Design. Games and Culture, 14(7-8), 843-855. https://doi.org/10.1177/1555412017740497

The Star Online. (2018). STEM literacy for industry 4.0. https://www.thestar.com.my/news/education/2018/10/21/stem-literacy-forindustry-40/

Tudor Car, L., Kyaw, B. M., Dunleavy, G., Smart, N. A., Semwal, M., Rotgans, J. I., . . Campbell, J. (2019). Digital Problem-Based Learning in Health Professions: Systematic Review and Meta-Analysis by the Digital Health Education Collaboration. J Med Internet Res, 21(2), e12945. https:/ / doi.org/10.2196/12945

van den Heuvel-Panhuizen, M., Kolovou, A., \& Robitzsch, A. (2013). Primary school students' strategies in early algebra problem solving supported by an online game. Educational Studies in Mathematics, 84(3), 281-307. https://doi.org/10.1007/s10649-013-9483-5

Vandercruysse, S., \& Elen, J. (2017). Towards a Game-Based Learning Instructional Design Model Focusing on Integration. In P. Wouters \& H. van Oostendorp (Eds.), Instructional Techniques to Facilitate Learning and Motivation of Serious Games (pp. 17-35). Springer International Publishing. https://doi.org/10.1007/978-3-31939298-1_2

Vecchia, R. D., Maltempi, M. V., \& Borba, M. C. (2015). The Construction of Electronic Games as an Environment for Mathematics Education. In T. Lowrie \& R. J. (Zevenbergen) (Eds.), Digital Games and Mathematics Learning: Potential, Promises and Pitfalls (pp. 55-69). Springer. https://doi.org/10.1007/978-94-017-9517-3_4

Wan Nor Fadzilah, W. H., Suhaiza, M. S., \& Halim, L. (2017). Pembudayaan STEM di Luar Bilik Darjah [STEM Enculturation Outside The Classroom]. Penerbit Universiti Kebangsaan Malaysia.

Williams, A. (2017). History of Digital Games: Developmenta in Arts, Design and Interaction. Routledge.

Wu, W. H., Hsiao, H. C., Wu, P. L., Lin, C. H., \& Huang, S. H. (2012). Investigating the learning-theory foundations of game-based learning: a meta-analysis. Journal of Computer Assisted Learning, 28(3), 265-279. https://doi.org/10.1111/j.13652729.2011.00437.x

Wu, Y.-T., \& Anderson, O. R. (2015). Technology-Enhanced STEM (Science, Technology, Engineering, and Mathematics) Education. Journal of Computer Education, 2(3), 245249. https://doi.org/10.1007/s40692-015-0041-2

Zaibon, S. B., \& Shiratuddin, N. (2010, 12-16 April 2010). Adapting Learning Theories in Mobile Game-Based Learning Development. 2010 Third IEEE International Conference on Digital Game and Intelligent Toy Enhanced Learning,

Zubek, R. (2020). Elements of Game Design. The MIT Press. 